Article

\title{
Electrical and Meteorological Data Acquisition System of a Commercial and Domestic Microgrid for Monitoring PV Parameters
}

\author{
Edson L. Meyer ${ }^{\circledR}$, Oliver O. Apeh * and Ochuko K. Overen \\ Fort Hare Institute of Technology, University of Fort Hare, Alice 5700, South Africa; emeyer@ufh.ac.za (E.L.M.); \\ ooveren@ufh.ac.za (O.K.O.) \\ * Correspondence: oapeh@ufh.ac.za; Tel.: +27-(0)-73-335-1857
}

Received: 12 October 2020; Accepted: 16 November 2020; Published: 18 December 2020

\begin{abstract}
This paper centers on the design and installation of a robust photovoltaic (PV)-based microgrid data acquisition system (DAS) that can monitor different PV systems simultaneously. The PV-based microgrid consists of three solar systems: off-grid, hybrid and grid-assisted systems, each with $3.8 \mathrm{kWp}$ located at SolarWatt park, Fort Hare Institute of Technology (FHIT), South Africa. The designed DAS is achieved by assembling and connecting a set of sensors to measure and $\log$ electrical and meteorological parameters from each of the three power plants. Meteorological parameters use a CR1000 datalogger while the electrical output parameters use a DT80 data logger. Calibration was done by voltage signal conditioning which helps to reduce errors initiated by analogue signals. The designed DAS mainly assist in assessing the potential of solar energy of the microgrid power plant considering the energy needed in the remote community. Besides, the simultaneous monitoring of the three systems ensures that the outdoor operating conditions are the same while comparing the logged data. A variable day and a week, data were used to verify the reliability of the system. The back of the array temperature was observed to be $42.7^{\circ} \mathrm{C}$ when solar irradiance was $1246 \mathrm{~W} / \mathrm{m}^{2}$. The ambient temperature and relative humidity were obtained at $21.3^{\circ} \mathrm{C}$ and $63.3 \%$, respectively. The PV current in all three systems increases with the solar irradiance and is highest around midday. The results obtained show that the designed DAS is of great interest in PV system developments.
\end{abstract}

Keywords: microgrid; PV power plant; PV system performance; solar energy; sustainable development; off-grid system; hybrid system; grid-assisted system; CR1000 data logger; DT80 data logger

\section{Introduction}

In the world today, data acquisition systems (DASs) serve as a link between electrical and meteorological environments. The system is broadly applied in the research laboratory for measuring and analysing scientific and engineering experiments, for PV plant assessment in different areas in institutions and industries. Obviously, electrical and meteorological parameters such as current and voltage signals, solar irradiance, ambient temperature, relative humidity, wind speed and directions are well compatible with DAS. The influence of these parameters is very essential in analysing the power performances in harsh remote areas [1]. Undoubtedly, DAS are normally integrated into off-grid or grid-connected PV systems, with the sense of measuring, recording as well as displaying data in the absence of operator or computer mediations. The system is designed to receive multiple input parameters with the help of parts made in the signal conditioning unit and can record data simultaneously from the diversity of various sensors and on PV systems. In variable weather 
conditions, DAS can readjust the signals and parameters, so as to suit the new environments [2]. Various components make up the DAS such as data acquisition software, signal processors, sensors, computers, communication link, database and so on [3]. Each of these components should function together to constitute a DAS [3].

Typically, a lot of DAS designs have been established in the literature [4-6]. Their architectures are based on either simulation or experimental methods. The majority of the simulation presented several ways for assessing the reliability of the solar PV system particularly to the project strategy and the economic perspectives $[7,8]$. Nevertheless, the viewpoint in estimating the accuracy of energy is pretty low with the simulation devices as compared to the experimental observations owing to the limited input parameters designated for it [9]. Therefore, the only available choice would be experimental studies. A prototype DAS for an off-grid PV power plant was proposed by [10], the system consists of a personal computer, simulator for PV modules and battery storage. The prototype was used to collect data to find out the execution of the power plant. The operation of PV modules under outdoor weather conditions was also a concern for [11]. To this effect, they designed a low-cost current-voltage (I-V) data acquisition system that was used to characterise seven modules subjected to outdoor weather. They argued that results obtained from their study could be adopted in interrogating and comparing PV ratings under realistic operating conditions. Based on their findings, Voc decreases with an increase in ambient temperature whereas photo-generated current and generated power increases linearly with irradiance. In another development, a simple enclosed system centered on DAS was reported in [12] while a web integrated DAS was discussed in [13].

However, for DAS to be continuously in action, PV power plants should be at the forefront. Thus, the components that accompany the operation of PV power plants include the charge controller (charge regulator or regulator), inverter and battery. The function of a charge controller is to protect the battery without impinging unnecessarily on system efficiency [14]. The charge controller controls the rate at which the batteries are charged (high voltage disconnection) and discharged (low voltage disconnection). Charge controllers are classified into maximum power point tracking (MPPT) and Pulse-Width Modulation (PWM) with respect to operation. The MPPT charge controller, which is commonly used for large-scale power plants, operates with an algorithm based on the exploitation of voltage and current variation due to instantaneous power pulsations [15]. PWM charge controller suitable for domestic PV power production takes into consideration that PV modules do not always give the power output due to weather variation. Hence, the PWM charge controller automatically matches the PV voltage with the battery voltage [16]. As the PV and battery produce DC power, an inverter is required to integrate generated power into the national grid or to power appliance and lighting in a house. An inverter is, therefore, a device that converts generated or supplied DC power from the PV or battery into AC power. PV inverters usually have one or two conversion stages. In a single inverter DC to AC, stage one conversion is commonly used, while stage two is DC to DC conversion. The battery bank provides storage for the generated power during the day for consumption in the absence of the sun (night and overcast sky days). That is the size of the battery is subjective by the capacity of the PV module as well as load. However, the system component balance of a commercial PV power plant (grid-tied) does not require a battery bank, as the converted AC power is fed directly to the national grid [17].

In view of this, and in line with the national imperative of the South African government, a $11.4 \mathrm{~kW}$ PV-based microgrid was designed and installed at the SolarWatt Park. The microgrid which is used to power a commercial and residential building is a pilot study of large- and small-scale PV power plants operation in Alice. However, this study is focused on various components of the microgrid with emphasis on the design and installation of electrical and meteorological DAS.

This paper is organised in the following ways: Section 2 highlights the site and microgrid descriptions while Section 3 discusses material and methods. Section 4 presents the results and discussion and a summary of the conclusion is presented in Section 5. 


\section{The Site and Microgrid Description}

\subsection{Site}

SolarWatt Park is located at latitude $32.8^{\circ}$ south and longitude $26.8^{\circ}$ east at an altitude of $540 \mathrm{~m}$ in Alice, Eastern Cape South Africa. Climatically, Alice is in the temperate interior (Zone 2) climate of South Africa [18] The grey climatic map of SABS that has been modified to multiple color and annual global horizontal irradiance of South Africa are given respectively in Figure 1a,b.
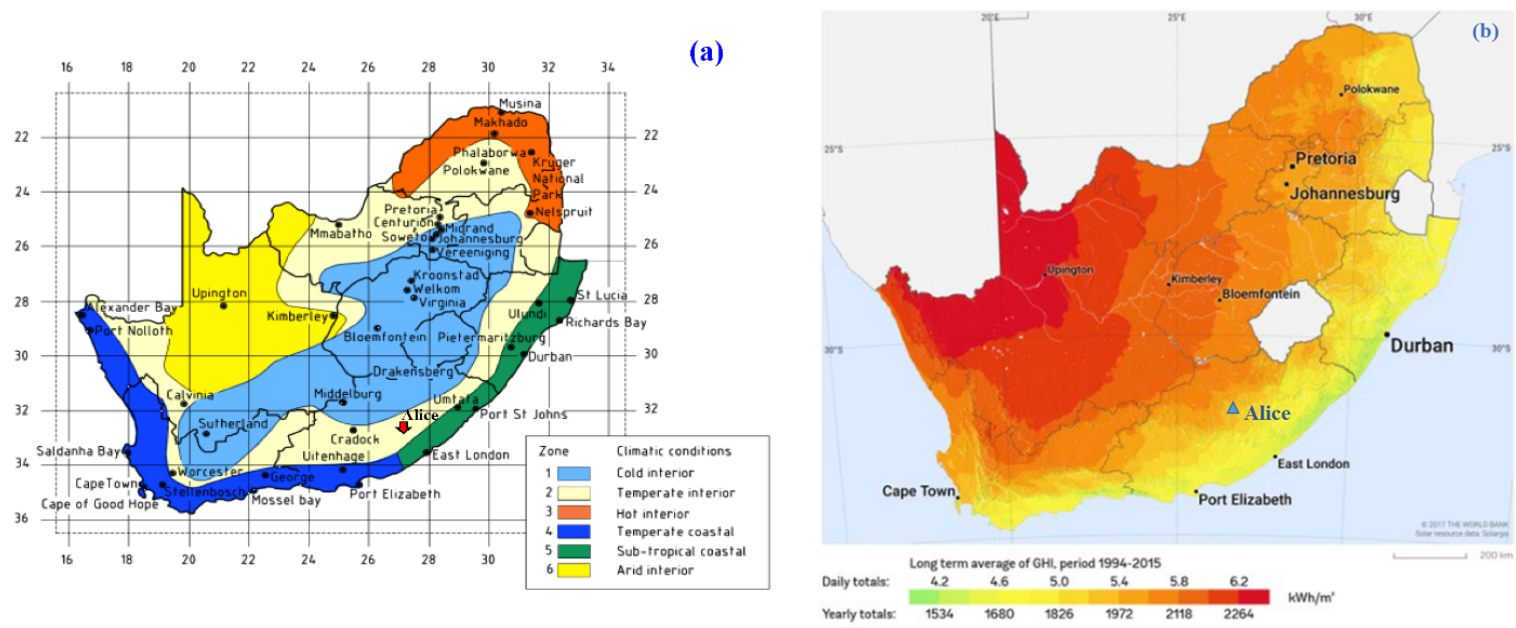

Figure 1. Location of Alice indicated in; (a) climatic map [18] and (b) 21 years average global horizontal irradiance distribution of South Africa [19].

The climate of Alice is characterised by a hot summer and mild (no snow) winter, with an average dry bulb temperature of $29^{\circ} \mathrm{C}$ and $15^{\circ} \mathrm{C}$, respectively. The east wind is predominant in summer while the winter is dominated by the west wind. An average wind speed of $2.5 \mathrm{~m} / \mathrm{s}$ is experienced in Alice throughout the year and average solar radiation of $606.06 \mathrm{~W} / \mathrm{m}^{2}$ in summer and $346.17 \mathrm{~W} / \mathrm{m}^{2}$ in winter [20]. According to SOLARGIS [19], Alice is among the third-highest global horizontal irradiance locations and potential of PV power generation in South Africa. Between 1994 and 2015, the total average daily global horizontal irradiation ranges from 5.4 to $5.8 \mathrm{kWh} / \mathrm{m}^{2}$ and annual irradiation of 1972 to $2118 \mathrm{~kW} / \mathrm{m}^{2}$ (see Figure 1b). The resultant daily and annual cumulative PV power generation was at 5.0 and $1826 \mathrm{kWh} / \mathrm{kWp}$, respectively over the same period.

The site (SolarWatt Park) was considered conducive for the PV power plant due to its un-obstructive daily solar path. It is also accessible with an asphalt-paved road linked to the main road and less than $1 \mathrm{~km}$ away from a national grid access point. The University where the site is located had also indicated that there was no plan to utilise the land for any agricultural or commercial purpose. Figure 1a shows the climatic map of Alice, the site shares the same climatic zone with Beaufort West, Ladysmith, Polokwane, Pretoria, and other places in the country where PV power generation is prevailing.

\subsection{Description of Microgrid Structure}

PV modules were assembled on the roof-top of a passive solar residential and commercial building. The roofs of both buildings were north facing with an inclination angle of $20^{\circ}$ for the residential and $12^{\circ}$ for the commercial building. The selected roof angles are not the optimum angle for PV power plant design but were constrained by the buildings' design. A photo of the PV module array is given in Figure 2. 


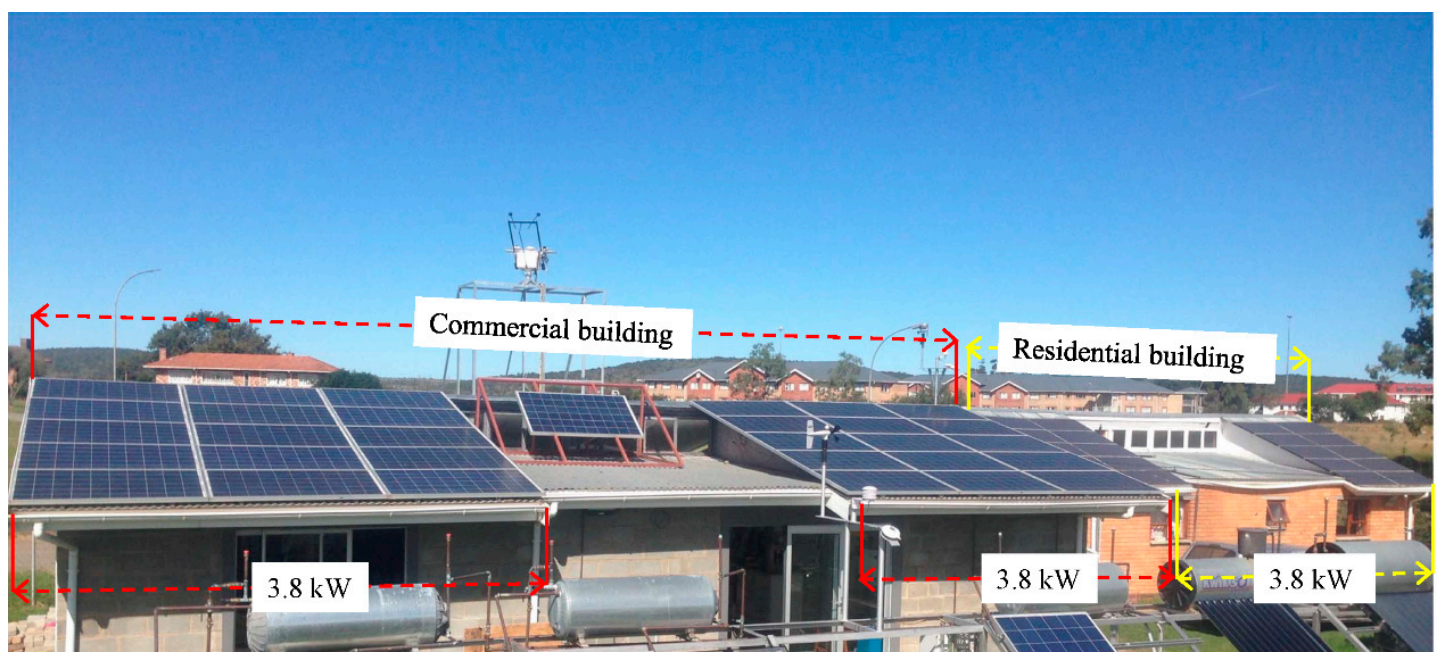

Figure 2. Rooftop mounted PV system in the SolarWatt Park.

However, the PV array in each building was divided into east and west wing. On the residential building, a total of 20 modules $\left(190 \mathrm{~W}_{\mathrm{p}}\right)$ occupy both wings of the roof; amounting to a peak power generating capacity of $3.8 \mathrm{~kW}$. In the PV array, two modules were connected in series to give $10 \mathrm{PV}$ parallel string (5 per wing) generator. On the commercial building, each wing on the roof contains 15 sets of 250 W PV modules with 3 modules connected in series to give a 5 PV parallel string. This results in a $3.8 \mathrm{~kW}$ peak power generator in each wing. The connections of the PV array are guided by the maximum operating voltage (Voc) of the charged controllers in the generators. Both generators in each building made up the PV power plant in this study. The generator in the residential building is off-grid while that in east and west wind of the commercial building are grid-assisted and hybrid PV systems respectively. The system component balance of the PV power plant is given in Figure 3.

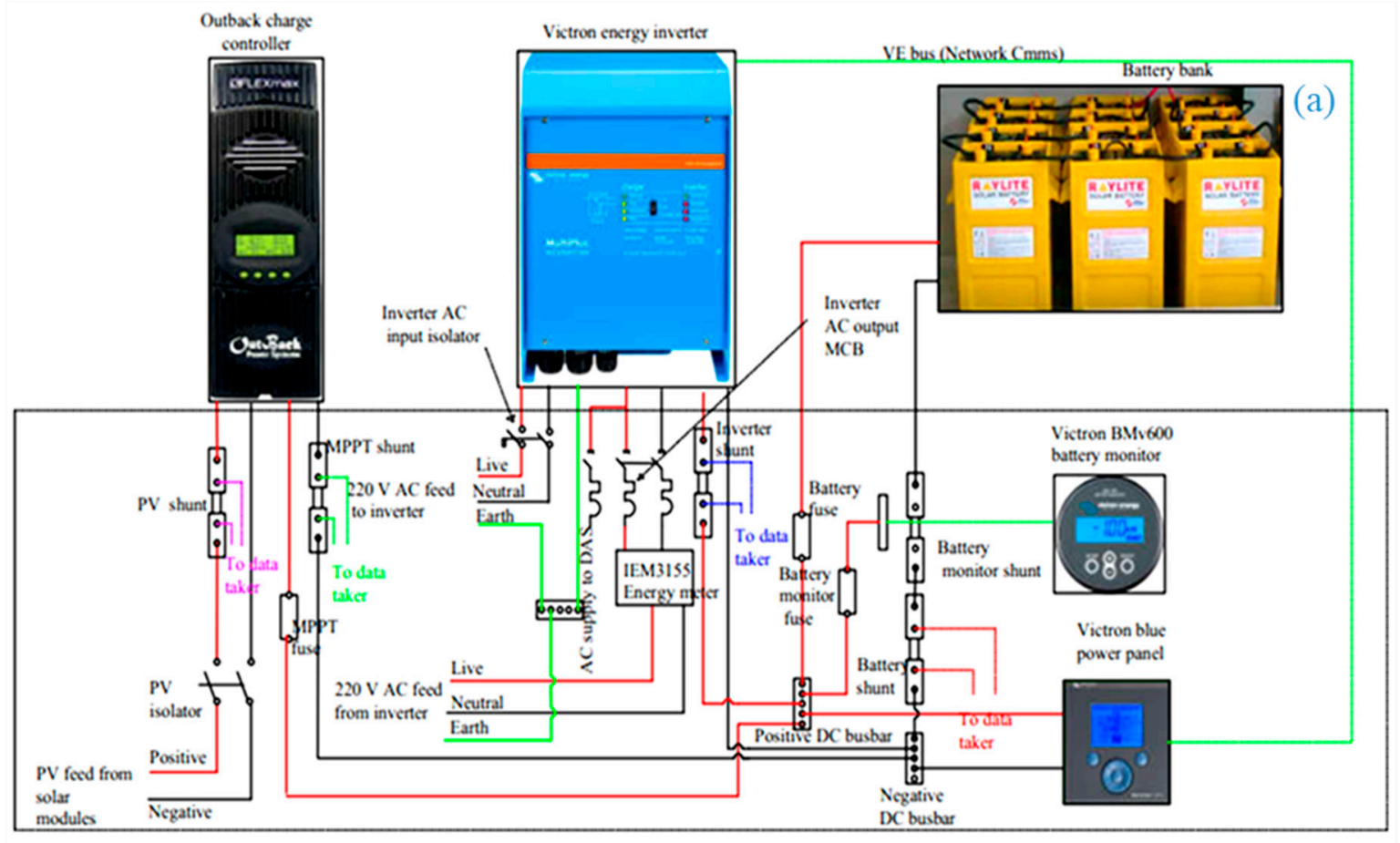

Figure 3. Cont. 

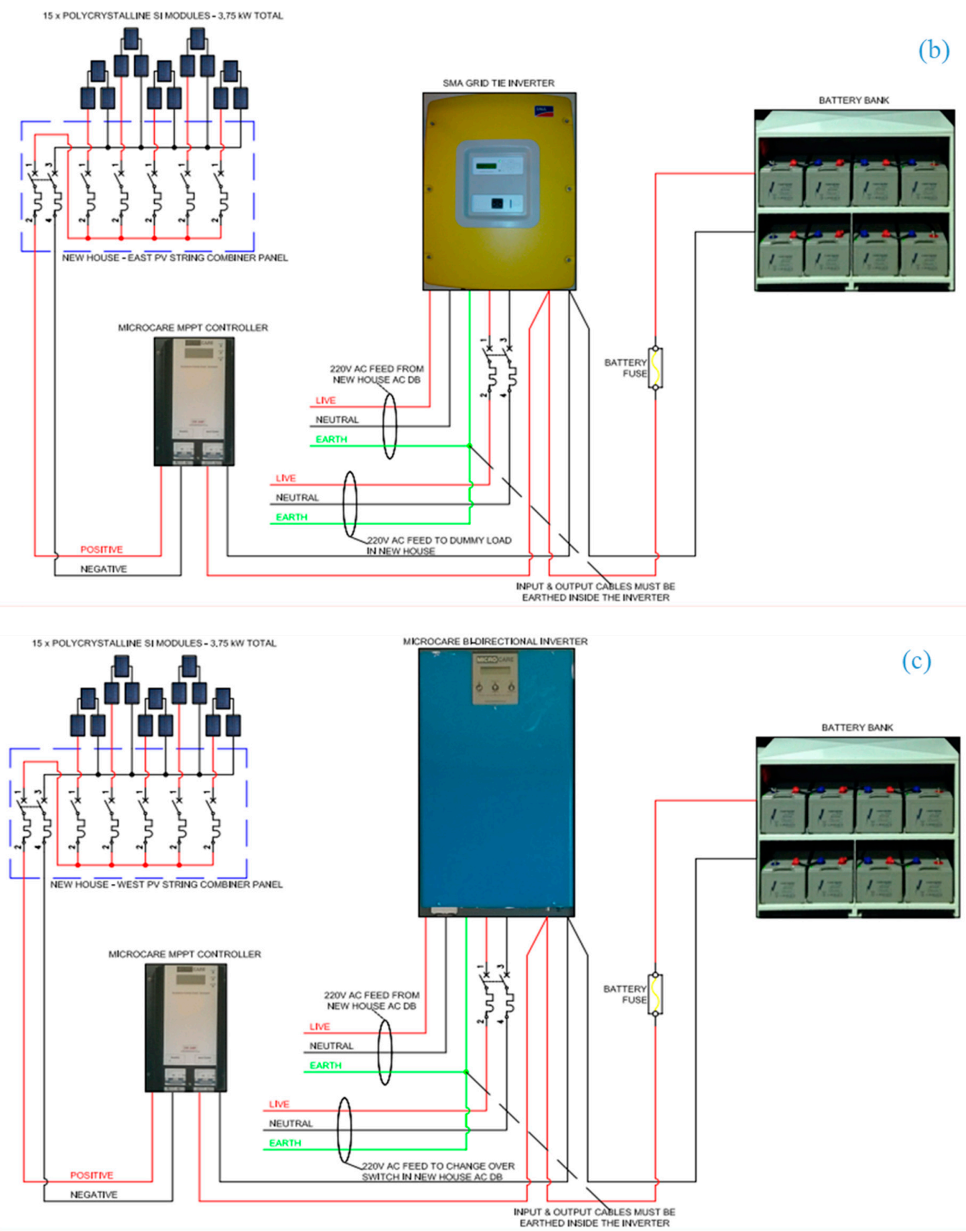

Figure 3. Wire diagram of the component balance of system in (a) off-grid, (b) hybrid, and (c) grid-assisted microgrid systems at SolarWatt Park.

In the context of this study, an off-grid (stand-alone) system uses solar energy as the sole source of electricity, whereas a grid-assisted system supplements solar energy with the national grid to provide electricity. A robust and effective load sizing, which matches utility consumption and the system component of the off-grid system was conducted to ensure an uninterrupted power supply. It should be noted that the load sizing of both buildings is outside the scope of this study. The selected load in the commercial building is powered by the grid-assisted system during peak solar energy period and backed up by the national grid when the battery power is low. Other loads in the commercial building are powered by the hybrid system and surplus solar energy generated is fed into the national grid. 
In terms of operation, a hybrid system is a combination of off-grid and grid assisted systems with the ability to feed and draw energy to and from the national grid. Based on the design of the systems, each system comprises a charge controller, inverter and battery bank.

As indicated in Figure 3, the grid-assisted and hybrid systems use a Microcare LCD MPPT 100 A charge controller, whereas FLEX Max 80 was used in the off-grid system. However, both charge controllers use a continuous MPPT algorithm to search for maximum available power in the PV array to charge their respective batteries. Like most MPPT charge controllers, the system charge controllers ensure optimum battery performance over a long period with three fundamental operation modes; Boost, Equalize, Float and Sleep mode. In addition, a bidirectional inverter in each of the systems is used to convert DC power from the charge controller (PV array or battery) to the consumable AC power of most appliances. In other words, the inverters can operate in uninterruptible power supply (battery charger) and inverter mode with the hybrid system's inverter equipped with grid connectivity function. The application of the inverters due to their multiple functions is predetermined by the user, following specified settings in the inverters. Therefore, all inverters were set to inverter mode since charge controllers are in-cooperated in the systems. A Sunny Island 5048 inverter was used in the hybrid system whereas Microcare L8/5000/48 and Victron energy Multiplus 48/5000 inverters were respectively used in the grid-assisted and off-grid systems.

Down the PV system, the component balance chain is the battery bank. As shown in Figure 3, each system has its battery bank. To this effect, a set of eight 6 V M-Solar 3MIL $25 \mathrm{~S}$ batteries connected in series was used in the off-grid system. Over $100 \mathrm{~h}$ discharge period, each battery delivers $900 \mathrm{Ah}$ with cell voltage above $1.85 \mathrm{~V}$ and a constant temperature of $25^{\circ} \mathrm{C}$. Trojan L16RE-2V and Hoppecke $6 \mathrm{OPzS}$ solar power batteries respectively made-up the hybrid and grid-assisted system. Both batteries are $2 \mathrm{~V}$, as such, 24 sets of batteries were connected in series in both systems. The Trojan battery is rated to deliver $1235 \mathrm{Ah}$ over $100 \mathrm{~h}$ while maintaining a voltage above $1.75 \mathrm{~V} /$ cell at $25^{\circ} \mathrm{C}$. At the same temperature and a constant cell voltage above $1.80 \mathrm{~V}$, the Hoppecke battery will deliver 910 Ah over $100 \mathrm{~h}$. These imply that in an open circuit and at full charge, the off-grid, hybrid and grid-assisted batteries can supply $43.20,59.28$, and $43.68 \mathrm{kWh}$, respectively in $100 \mathrm{~h}$.

\subsection{Practical Scenarios of DAS in the PV Industry}

The DAS in PV systems normally comprises of monitoring the electrical side of the system with limited monitoring of the operating conditions affecting these performance values [21]. From experience, we know that the relation between performance and operating conditions or degradation and operating conditions are crucial to understanding the intricacies of PV systems. Most commercial of domestic installed systems are by nature not interest in meteorological conditions and only on the electrical output.

However, for the sake of fully understanding the relationship between operation and operating conditions, it is necessary to have a synchronized electrical and meteorological data acquisition system. This enables the formulating of formal relations between the operating performance parameters and operating conditions. In this study, the DAS was developed from individual components and is not commercially available. The novelty of the DAS in its most fundamental form is the electrical isolation circuitry as discussed in Section 3.3 below where high PV module voltages are electrically isolated from signal voltages connected to the data acquisition side of the DAS. As we have not employed any commercially available DAS cards, the scope of this study excludes a comparative study.

\section{Materials and Methods}

\subsection{Design and Development of DAS}

The sun generates solar energy that is used by the PV array. The photovoltaic system incorporates solar array, meteorological and electrical parameters with different techniques for data transmissions. The CR1000 consists of sets of sensors for measuring and logging in meteorological parameters such as solar irradiance, ambient temperature, relative humidity and wind speed while DT80 consists of 
different sets of devices used to measure electrical parameters like current and voltage of PV, MPPT, battery and inverter. Temperatures between 17 to $45^{\circ} \mathrm{C}$ with relative humidity conditions within a range from 15 to $90 \%$ (non-condensing) and solar irradiance of up to $1250 \mathrm{~W} / \mathrm{m}^{2}$ were recorded in the system. Besides, the designed DAS was exposed to dust and high wind speed in the range of 2.1 to $2.5 \mathrm{~m} / \mathrm{s}$. A refrigeration system and a stove of up to $2 \mathrm{~kW}$ were used to draw power from the PV array and battery system. Figure 4 shows the block diagram of DAS measuring indoor and outdoor parameters.

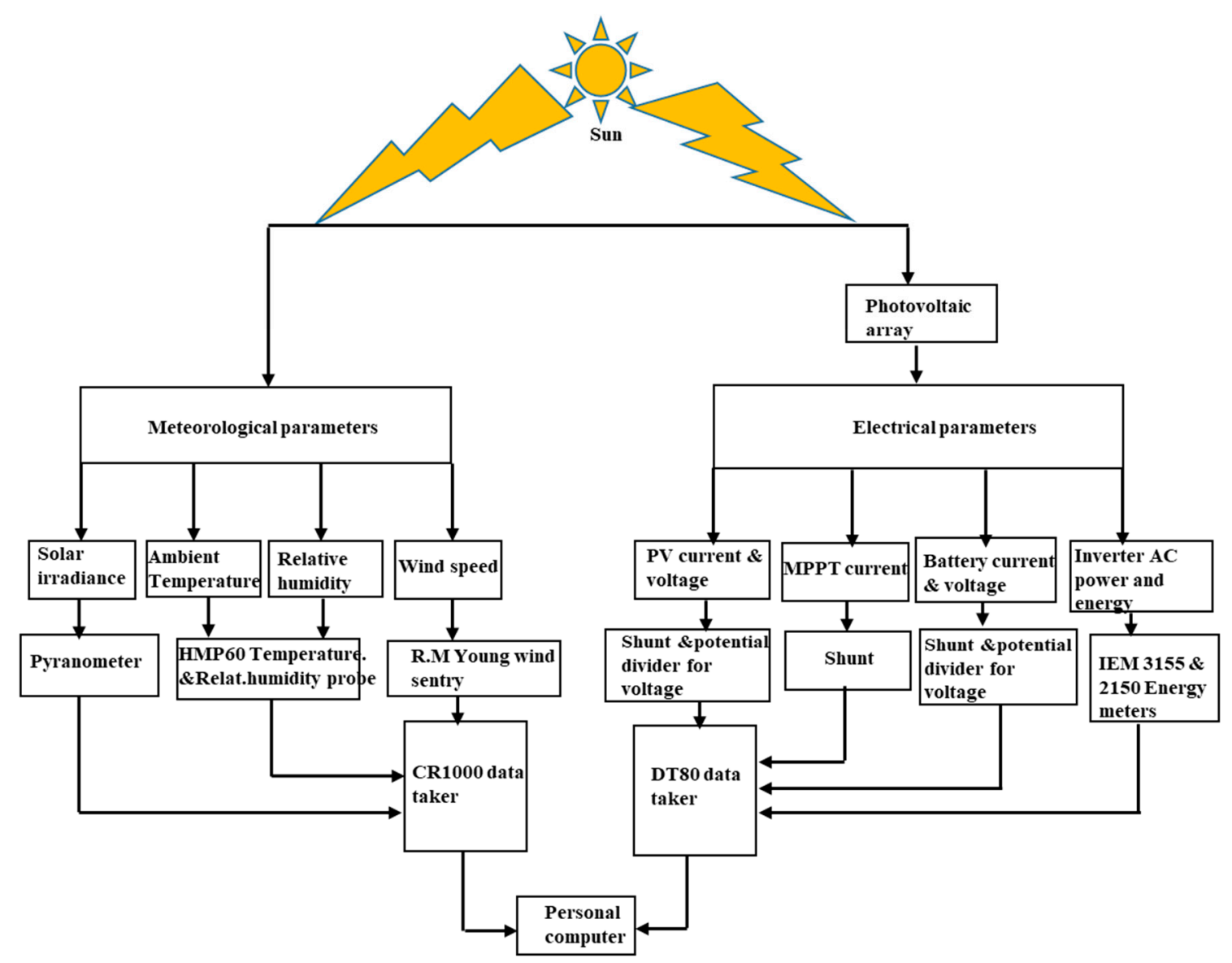

Figure 4. Schematic view of the meteorological and electrical parameters with sensors for the DAS.

Shunt resistors are aligned, each at the output of the PV array and MPPT while the input in each is connected to the battery bank and the inverter to measure the current flowing into and out of the respective components. The DC power output from the batteries is fed directly into the inverter for conversion into AC power at a frequency of $50 \mathrm{~Hz}$ and voltage of $230 \mathrm{~V}$. The output current, voltage and power from the inverter are measured using the IEM 2150 energy meters. However, the two loggers (CR1000 and DT80) automatically record each reading taken from the respective sensor which is at that point stored in the internal memory of the corresponding loggers and can henceforth retrieve periodically through Wi-Fi to the personal computer for analysis.

\subsection{Development of Meteorological DAS}

The meteorological data acquisition is carried out to offer additional data to PV array and also assists to address the desires of the PV power plant for long-standing, high accuracy, well preserved and standard systems in variable weather conditions. The measuring parameters are pyranometer for solar radiation, relative humidity probe for both ambient temperature and relative humidity as well as 
wind monitor for wind speed. These devices are all mounted at the roof-top of the commercial building at SolarWatt park, to experimentally measure metrological parameters at different positions of the sun.

The solar radiation measurements comprise a SOLYS 2 sun tracker, which contains two pyranometers, Pyrheliometer and pyrgeometer. The sun tracker is a fitted device capable of measuring global, direct and diffuse components of the sun as well as other meteorological parameters. It is an automatic two-axis instrument used for both vertical and horizontal solar radiation with a team of measuring devices such as the time, date, longitude, latitude and altitude of this location to calculate and track the position of the sun at all the time. Hence, the image of the sun tracker is presented in Figure 5.

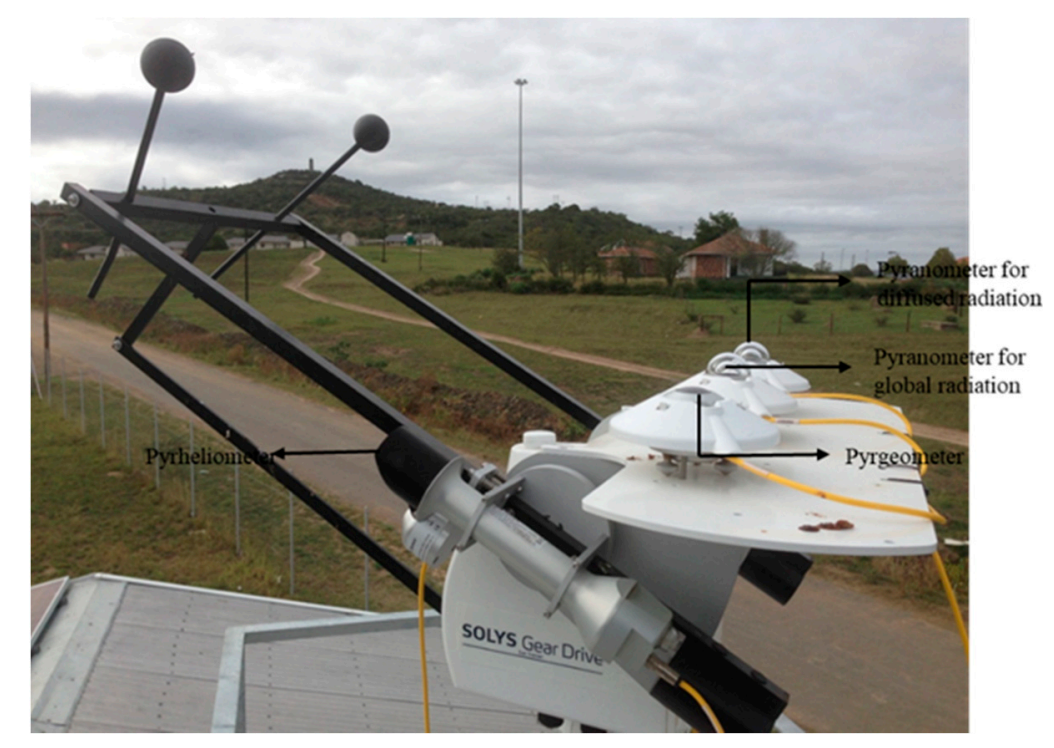

Figure 5. The Sun tracker comprising pyrheliometer, pyranometers and pyrgeometer with the black balls shading the horizontal instruments.

However, as shown in Figure 6, Kipp \& Zonen CMP 11 pyranometers were used to monitor the global horizontal irradiance (GHI) and global irradiance on a tilted surface. The tilted pyranometer (extreme right) is on the same slope $\left(12^{\circ}\right)$ as the roof of the commercial building, thus, measuring the same amount of solar radiation subjected to the PV array. CMP 11 pyranometer is made up of a 32-junction thermopile as a sensing element. The thermopile involves thermocouple junction with sets that were in series connection.

The measurement (hot) junction of one of the thermocouple absorbs thermal radiation, increasing its temperature. The difference between the measurement and a fixed temperature reference (cold) junction produces a voltage directly proportional to the differential temperature created due to the thermoelectric effect [22]. The sensitivity of the CMP 11 used in this study is $8 \mu \mathrm{V} / \mathrm{m}^{-2}$ with a spectral range of 285 to $2800 \mathrm{~nm}$. Its response time is less than $1.7 \mathrm{~s}(63 \%)$ and $5 \mathrm{~s}(95 \%)$ [23]. The weather station was elevated by $1 \mathrm{~m}$ above the roof, providing unobstructed solar radiation for the radiometers. The weather station was also strategically located such that it does not cast a shadow on the PV array.

Furthermore, the 6-plate natural aspirated radiation shield in the middle of the weather station, house the temperature and relative humidity probe. The white painted radiation shield allows it to reflect solar radiation, whereas, allows the natural free flow of air through the louvers. This mechanism keeps the probe close as possible to the ambient air temperature (eliminating solar effect) and water vapour [24]. The HMP60 temperature and relative humidity probe measure the outdoor air temperature, and relative humidity using a platinum resistance temperature (PRT) detector to measure air temperature [25] and a capacitive relative humidity sensor to measure relative humidity [26]. The measurement specifications of HMP60 probe temperature and relative humidity sensor are given in Table 1 [24]. 


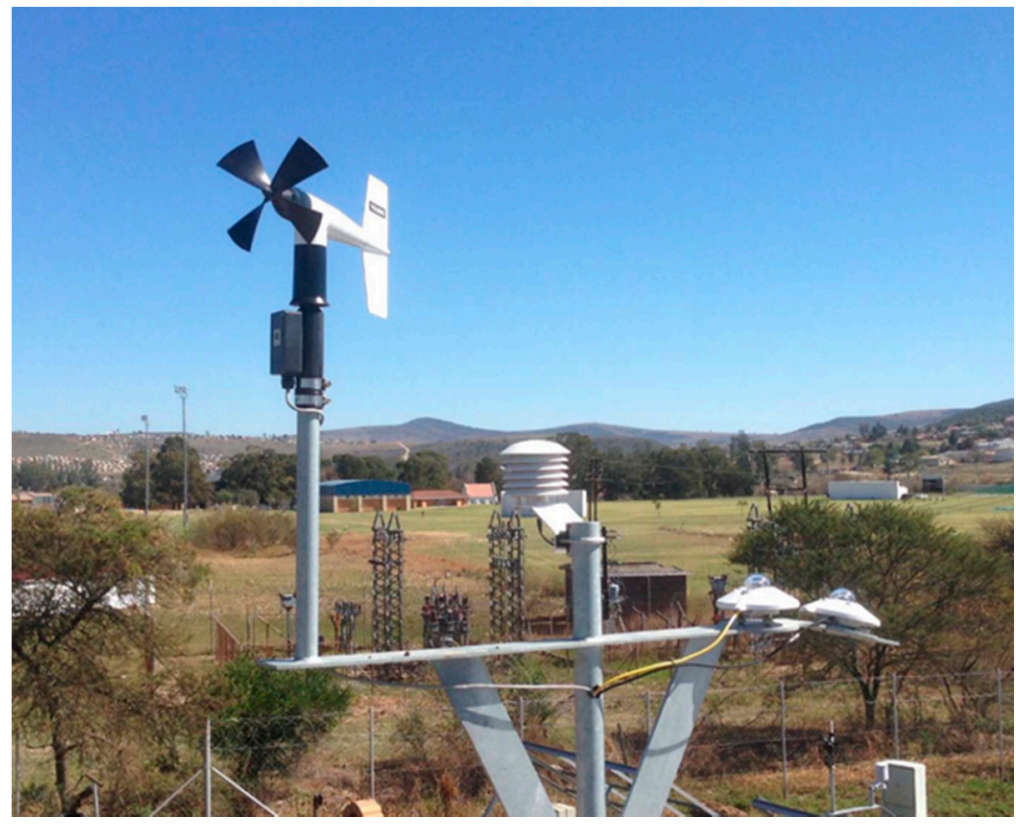

Figure 6. Setup weather station used in measuring ambient air temperature, relative humidity, solar radiation, wind speed and direction.

Table 1. HPM 60 temperature and relative humidity sensors specification.

\begin{tabular}{cccc}
\hline Parameters & \multicolumn{2}{c}{ Measurement Range } & Accuracy $( \pm)$ \\
\hline Temperature $\left({ }^{\circ} \mathrm{C}\right)$ & \multicolumn{2}{c}{-40 to 60} & 0.6 \\
\hline \multirow{3}{*}{ Relative humidity $(\%)$} & at 0 to 40 & 0 to 90 & 3 \\
\cline { 2 - 4 } & & 90 to 100 & 5 \\
& at 0 to 40 & 0 to 90 & 5 \\
& and 40 to 60 & 90 to 100 & 7 \\
\hline
\end{tabular}

All sensors were connected to a CR1000 were they are scanned in 10 min interval and data store every $30 \mathrm{~min}$. Meanwhile, a 12 Volt DC power supply was used to power the CR1000. The power supply was complemented with a 12 Volt rechargeable battery and an uninterruptable power supply system.

\subsection{PV System Electrical Performance DAS}

In all the three PV systems, the electrical performance measurements cover the PV, charge controller, battery and inverter current. Regarding the voltage, the PV and battery voltages were measured, where the PV voltage is in the same potential as the charge controller input voltage. Likewise, the battery voltage is equivalent to the charge controller output and inverter input voltages. In addition to the current and voltage measurements, the inverter output voltage, power and energy in all the systems were monitored. All the measuring sensors and devices were connected to a DT80 dataTaker accompanied by a CEM 20 channel expansion module, where data are stored and retrieved periodically. The PV systems electrical parameters data acquisition system are presented in Figure 7. 


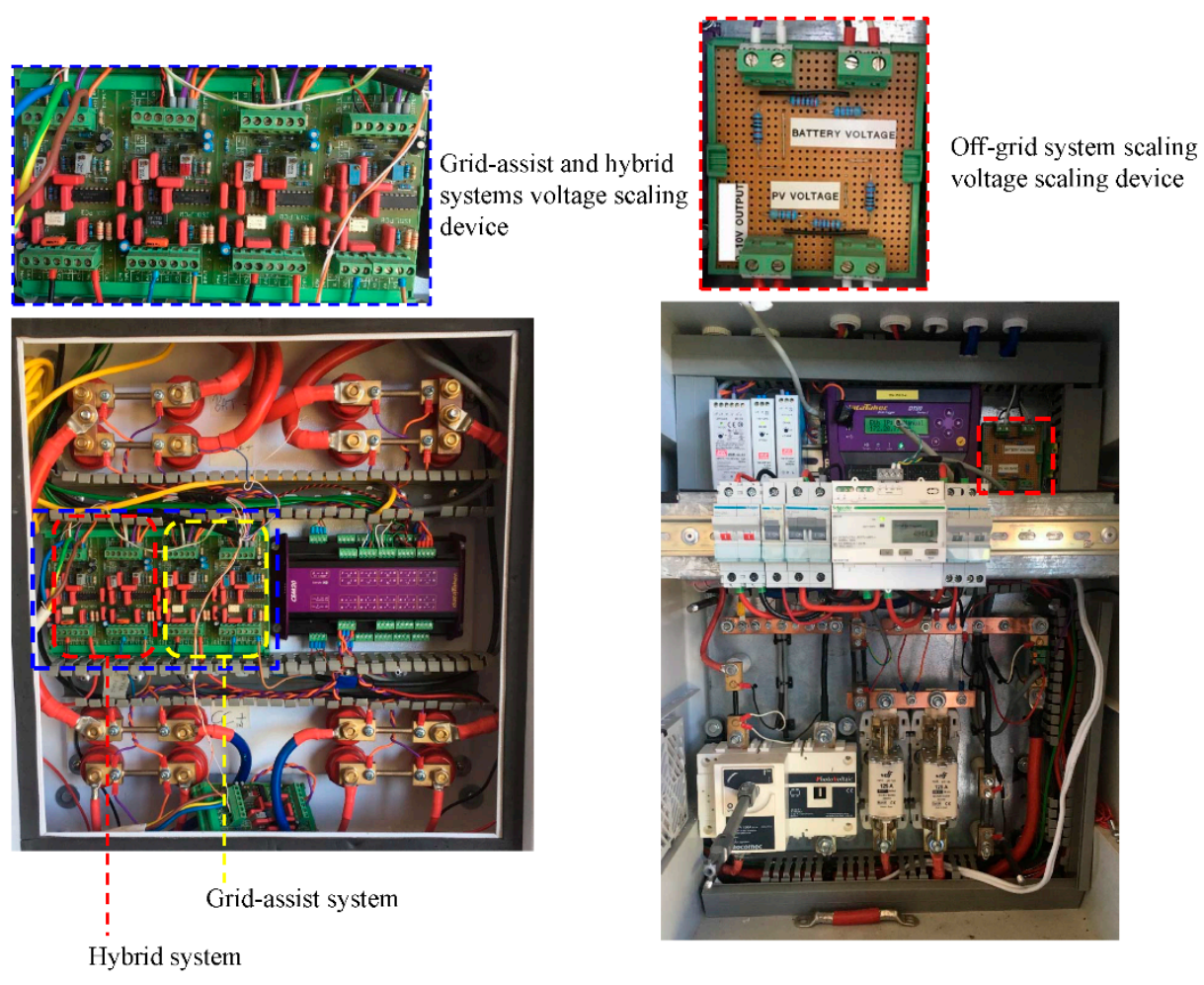

Figure 7. The PV systems electrical parameters data acquisition system indicating the three systems' voltage scaling devices and other measuring instruments.

In the off-grid system, an $80 \mathrm{~A}$ shunt resistor with a voltage drop of $50 \mathrm{mV}$ was used for the current measurements. The grid-assisted and hybrid systems both use $100 \mathrm{~A}$ shunt with a corresponding voltage drop of $60 \mathrm{mV}$ for the same measurements. The current flowing through the shunt resistors is proportional to the drop voltage, and it is logged using a defined voltage to the current multiplier in the dataTaker.

Meanwhile, voltage measurements were not as straight forward as that of the current. The DT80 dataTaker is designed to directly measure $30 \mathrm{mV}$ to $30 \mathrm{~V}$ DC voltage, whereas full-scale open circuit PV and battery voltages were 120 and $60 \mathrm{~V}$, respectively. Therefore, a voltage scaling device was required to scale-down the PV and battery voltages. Thus, $80 \mathrm{k} \Omega$ potential divider network devices were used to scale-down the PV and battery voltages of the off-grid system. In the grid-assisted and hybrid systems, a signal conditioner circuitry with the ability to scale and isolate voltage was used. The voltage scaling devices in each system were configured to receive $120 \mathrm{~V}$ (input) and scale it down to 10 (output) VDC for the dataTaker. It is worth mentioning that the electrical isolation of the input and output voltages of the various components as stated above was not considered in the design of the voltage scaling devices since the dataTaker is equipped with mechanical relays. These relays allow the dataTaker to measure each voltage signal at any given time individually.

On the other hand, the voltage divider method can be used to measure the PV and battery voltage in the system. In this process, three resistors of resistances were connected in series: $43 \mathrm{k} \Omega, 27 \mathrm{k} \Omega$ and $10 \mathrm{k} \Omega$. The data taker was connected across the $10 \mathrm{k} \Omega$ resistor. This is to allow the taker to record the minimum available voltage. The data logger has been configured to multiply this measured voltage by a channel factor of 8 to convert the voltage drop being measured by the data logger into the actual PV or battery voltage. Figure 8 shows the arrangement of the resistors used to measure DC voltage in the system. 


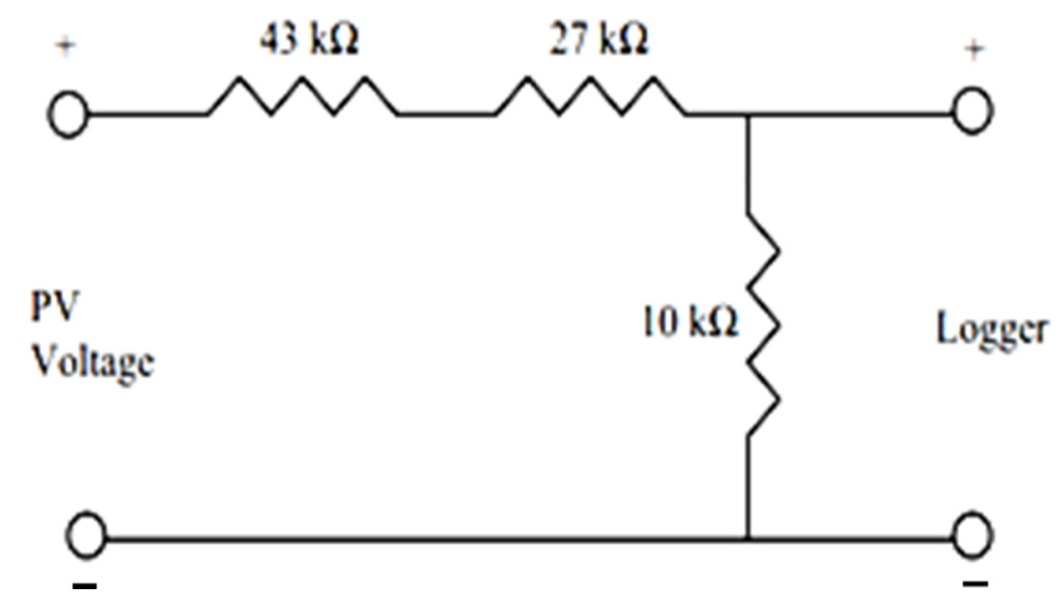

Figure 8. Set-up of signal conditioning using voltage divider approach

Hence the Equations (1) and (2) illustrate the voltage divider method on the circuit [27].

$$
\begin{gathered}
\mathrm{V}_{\text {out }}=\frac{\mathrm{V}_{\text {in }} \times 10 \mathrm{k} \Omega}{80 \mathrm{k} \Omega} \\
\mathrm{V}_{\text {out }}=0.125 \mathrm{~V}_{\text {in }}
\end{gathered}
$$

Furthermore, a three-phase Schneider IEM 3155 energy meter was used to monitor the off-grid system's inverter output voltage, power and energy. The same parameters in the grid-assisted and hybrid systems were measured with a single-phase Schneider IEM 2150 energy meter installed in the respective systems. Both meters are rated $63 \mathrm{~A}$, whereas IEM 3155 can accommodate 100 to $480 \mathrm{~V}$ and IEM 2150 has a rating of $230 \mathrm{~V}$. They also have the ability to sub-billing, partial metering, and tariff; with IEM 3155 offering four tariff inputs [28,29].

\subsection{Calibration of Signal Conditioner}

Signal conditioner is usually required to convert analogue voltage signals to readable signals for digital devices (DT80 dataTaker) by the linearization process [30]. The converted signals are, however, a signal with a very low span; in other words, small output range. For this reason, the conditioning of the sense-element output begins with a gain stage which is usually prone to various sources of amplifier errors such as offset, gain and nonlinearity errors. The errors can be worsened or improved based on the way the conditioned output signal is calibrated before transmission in the monitoring system [24,29].

To this effect, the signal condition was calibrated to reduce errors initiated by the analogue signal non-idealities and as such improving the accuracy of the output sensor. Moreover, the input and output circuitry was isolated from the signal-conditioning circuits to scale down the input voltage $\left(\mathrm{V}_{\text {in }}\right)$ of $120 \mathrm{~V}$ to output voltage $\left(\mathrm{V}_{\text {out }}\right)$ of $10 \mathrm{~V}$. Figure 9 illustrates the signal conditioning process. 


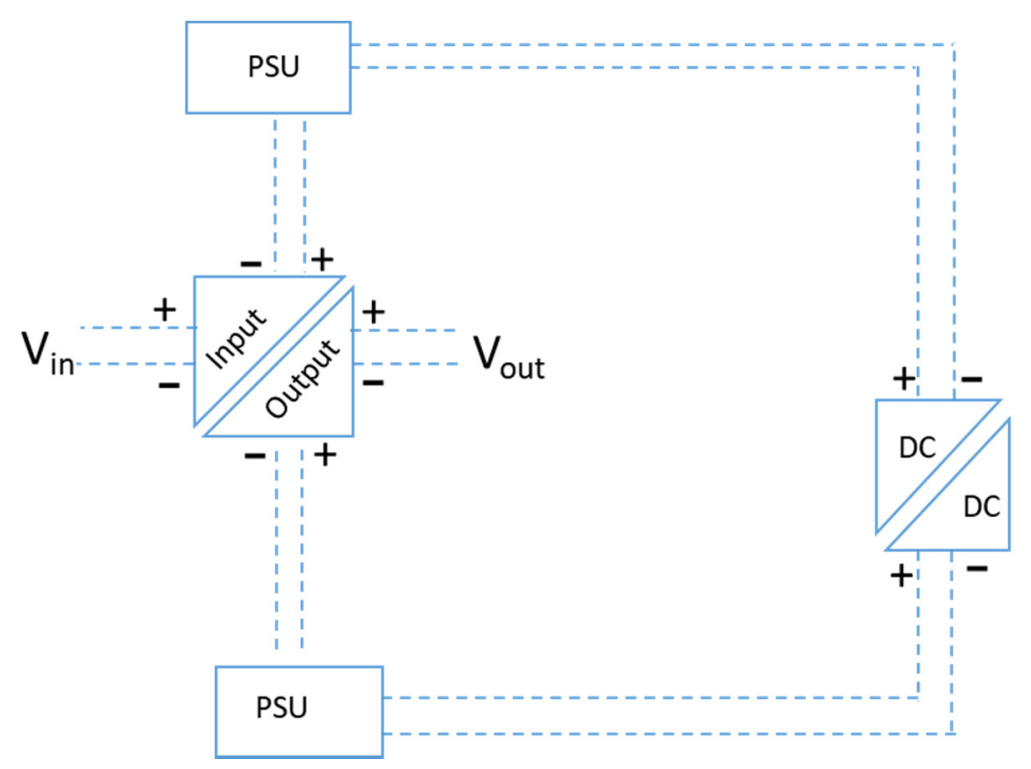

Figure 9. A block diagram of a signal conditioner.

The power supply unit (PSU) in Figure 9, ranges from $-15 \mathrm{~V}$ to $15 \mathrm{~V}$. The $120 \mathrm{~V}$ is fed directly via the input side of the isolation board to the DC to DC converter which comes out as $10 \mathrm{~V}$ from the isolator. To linearise the sensor, the $120 \mathrm{~V}$ input from the PV arrays was initially set at $80 \%$ of $120 \mathrm{~V}$ (full scale) reading $96 \mathrm{~V}$ in the multimeter and the span was gradually adjusted until it reached $8.0 \mathrm{~V}$ output. On the other hand, the span was set to the lowest value $20 \%$ of $120 \mathrm{~V}$ (full scale), reading $24 \mathrm{~V}$ in the multimeter, the span was equally readjusted to $2.0 \mathrm{~V}$ of the output. The process continued until an ideal output was obtained as expressed by a straight-line graph shown in Equation (3).

$$
\mathrm{V}_{\text {out }}=\mathrm{mV}_{\text {in }}+\mathrm{C}
$$

where $V_{\text {out }}$ is the output voltage and $V_{\text {in }}$ is the input voltage, $m$ is the slope and $C$ is the intercept. Equation (4) was used to test the actual value from PV with the output voltage values from the dataTaker.

$$
\mathrm{V}_{\text {out }}=\frac{\omega}{120} \times 10
$$

where $\omega$ is the measured voltage. However, the relation between the actual and logged values was examined and observed that they correlate quite well for all three systems. Figure 10a-c shows the regression distribution of the input and output voltages of each of the systems.

The bar charts in Figure 10 represent the actual differences between the actual $\left(\mathrm{V}_{\text {in }}\right)$ and dataTaker measured voltages. As observed, a relatively insignificant difference was observed between both voltages. The hybrid system was found to have the highest actual difference with $1.5 \%$ which is equivalent to $1.32 \mathrm{~V}$.

To establish whether signal conditioning is worsening or improving the conversion of actual input voltage to logger output, the percentage difference between the average $V_{\text {out }}$ before signal conditioning and the $\mathrm{V}_{\text {out }}$ after signal conditioning. Table 2 lists the average percentage difference before and after signal conditioning for the three systems in question. It is clear that signal conditioning is imperative to improve the stability and accuracy of the output signal of the analogue measurement sensors and in this case, an improvement of up to $43 \%$ can be achieved through signal conditioning. 

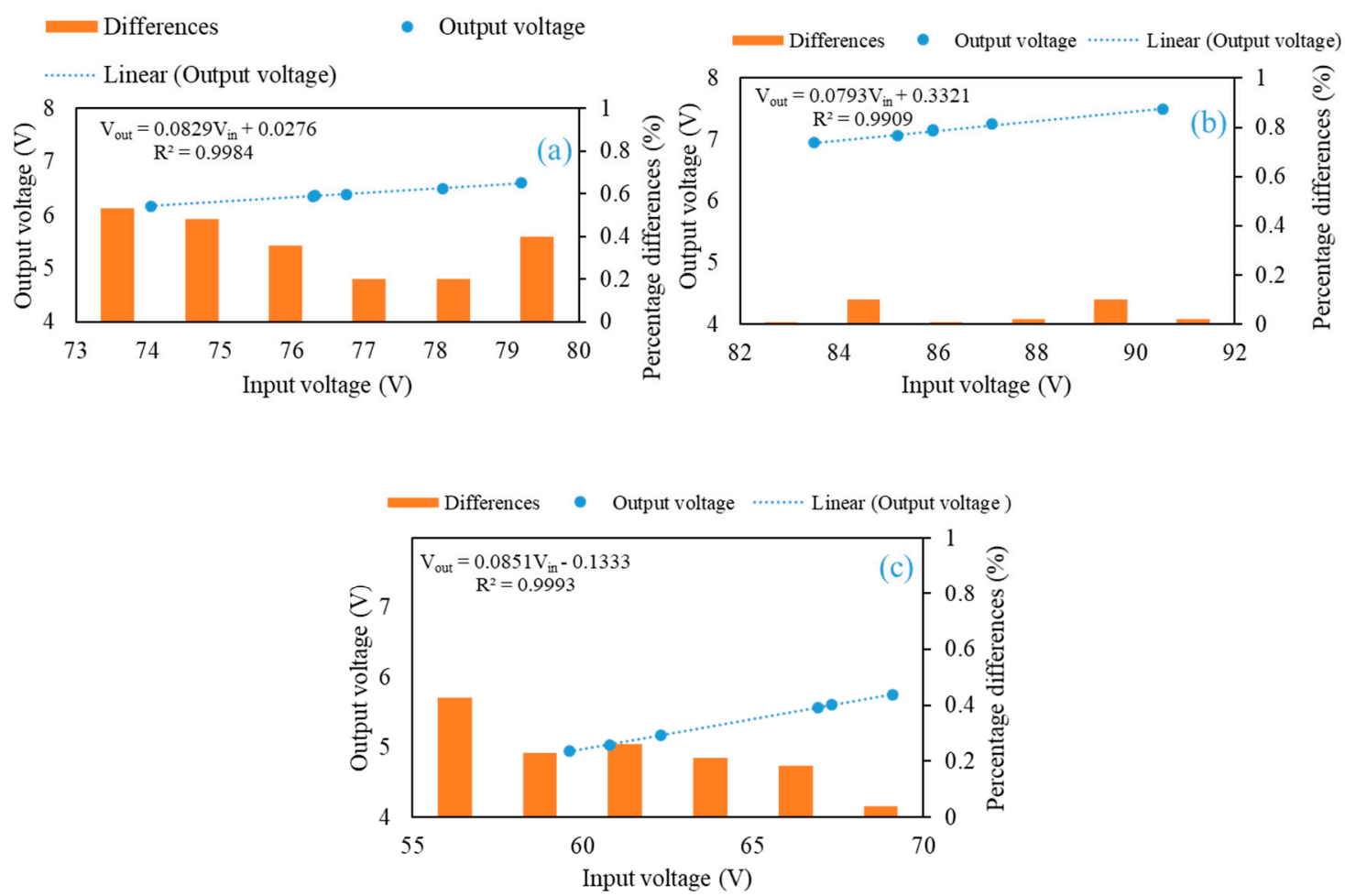

Figure 10. Regression distribution in (a) off-grid, (b) hybrid and (c) grid-assisted PV systems' signal conditioner linearization.

Table 2. Average percentage difference before and after signal conditioning for the three systems.

\begin{tabular}{cccc}
\hline & \multicolumn{2}{c}{ Average \% Difference before and after Signal Conditioning } \\
\cline { 2 - 4 } & Off-Grid System & Hybrid System & Grid-Assisted System \\
\hline $\mathrm{V}_{\text {out }}$ before signal conditioning & 0.37 & 0.07 & 0.39 \\
$\mathrm{~V}_{\text {out }}$ after signal conditioning & 0.26 & 0.04 & 0.23 \\
\% signal improvement & 29.73 & 42.86 & 41.03 \\
\hline
\end{tabular}

\section{Results and Discussion}

In this section, the performance of each PV system regarding production as captured by the DAS was covered. Knowledge of DAS is essential to allow for efficient planning and applications of the PV power plant. Besides, the optimum design and analysis require not only the information about solar irradiance but also other weather parameters that are collected for a long period. This is very important for power accessibility especially in a remote area that is far from grid connections. The monitored meteorological parameters such as solar radiation, air temperature, relative humidity, wind speed and direction as well as module temperature were also discussed. Thus, a week weather data of the premises and corresponding PV power production were presented and analysed.

\subsection{Analysis of Measured Ambient Weather Parameters}

The PV power plant and all the sensors in the installed DAS were tested with a week of data, starting from 1st to 7th February 2019, the summer month, to authenticate the reliability of the system. The abovementioned measured ambient weather conditions are presented in Figure 11a,b. The module temperature is the average back-of-module surface temperatures of all PV systems. 


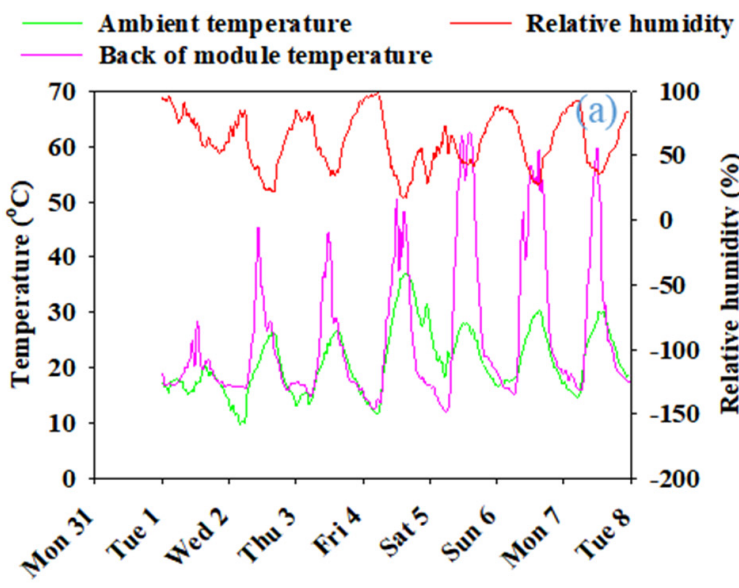

Days of the week

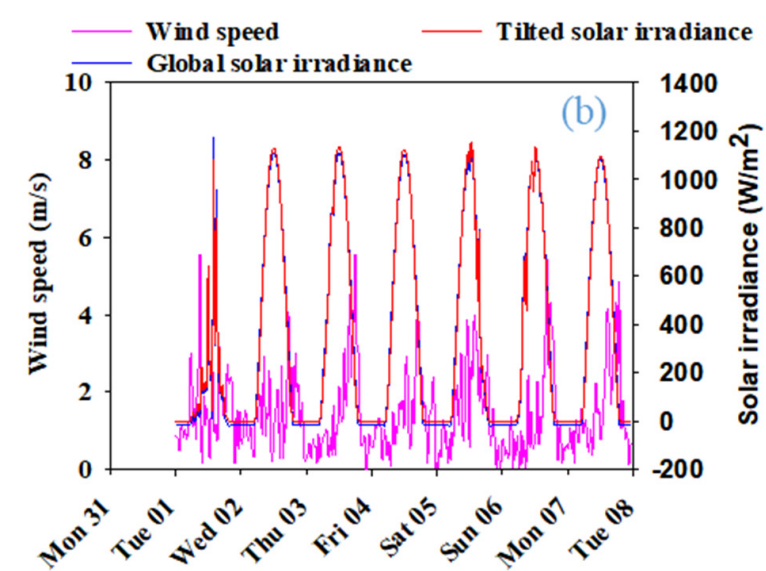

Days of the week

Figure 11. A week of ambient weather conditions of (a) temperature and relative humidity (b) wind speed and solar irradiance against days of the week at SolarWatt Park.

As seen in Figure 11, the module temperature was observed to follow the solar radiation (tilted and GHI) as well as air temperature closely. It should be noted that the overlapping tilted and horizontal surfaces' irradiance is due to the season (summer) in the measurements were conducted. In the winter season, a different irradiance is expected on both surfaces with a higher irradiance obtained during solar noon on the tilted surface. The varying seasonal irradiance on both surfaces is attributed to the low sun angle experienced in winter as compared to summer. The air relative humidity and wind speed are decreasing factors of the module temperature. Theoretically [31], at a fixed amount of water vapour in the air, an increase in temperature reduces air relative humidity and vice versa. The above findings tend to agree with the theory. Among some of the effects of wind speed on PV performance, it reduces the module temperature by the dissipation of convective heat transfer [32]. Nonetheless, the decrease in the module temperature at the peak wind speed period in Figure 11 cannot be wholly attributed to the cooling effect of wind. As peak wind speed period coincides with sunset. The direction is a major influencing factor of the wind cooling effect. Thus, a wind rose profile was developed and given in Figure 12.

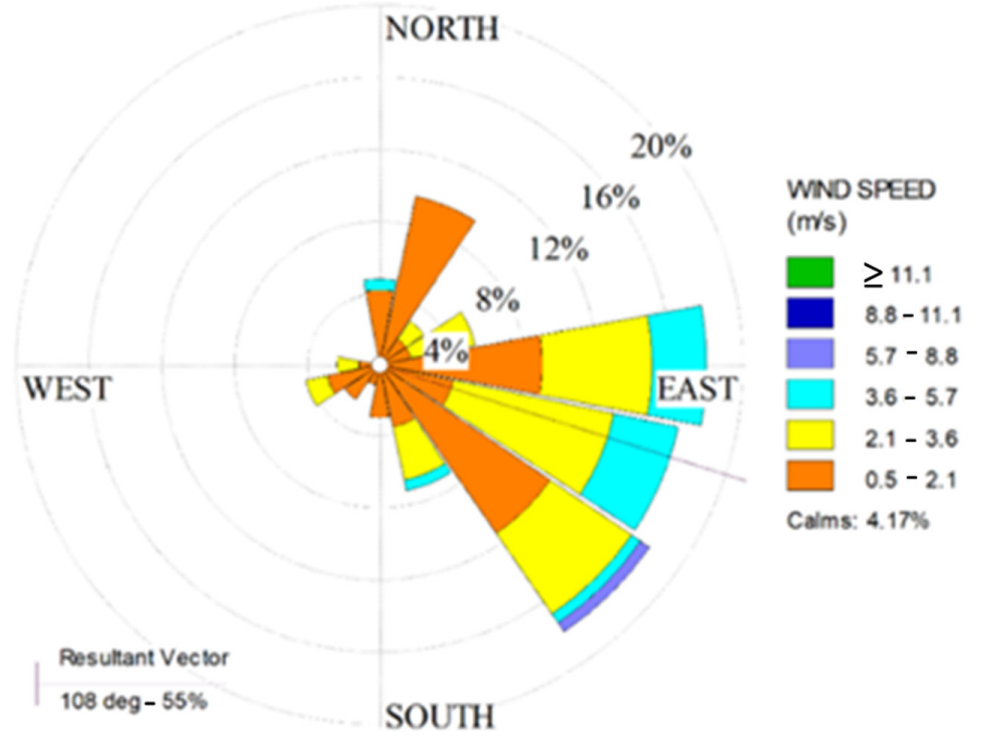

Figure 12. A wind rose profile of the PV power plant's premises over a week. 
Measured wind speed and direction data were integrated into the hourly interval and was used to develop the wind rose profile. The predominant wind showed by the resultant vector which was determined by the frequency count of the mean wind direction. As shown in Figure 12, 55\% of the wind with a mean direction of $108^{\circ}$ was observed to blow from the southeast; serving as the prevailing wind. Therefore, the wind direction favours the PV module regarding cooling as the predominant airflow is in the opposite direction of the PV array.

However, Figure 13 shows a typical day profile of irradiance, relative humidity, array and ambient temperatures of a variable day with a rainstorm on 11th February 2019. The data collected by the data logger displays a nice correlation despite the variable weather conditions. The data loggers functioned properly without faults in the day of stormy weather.

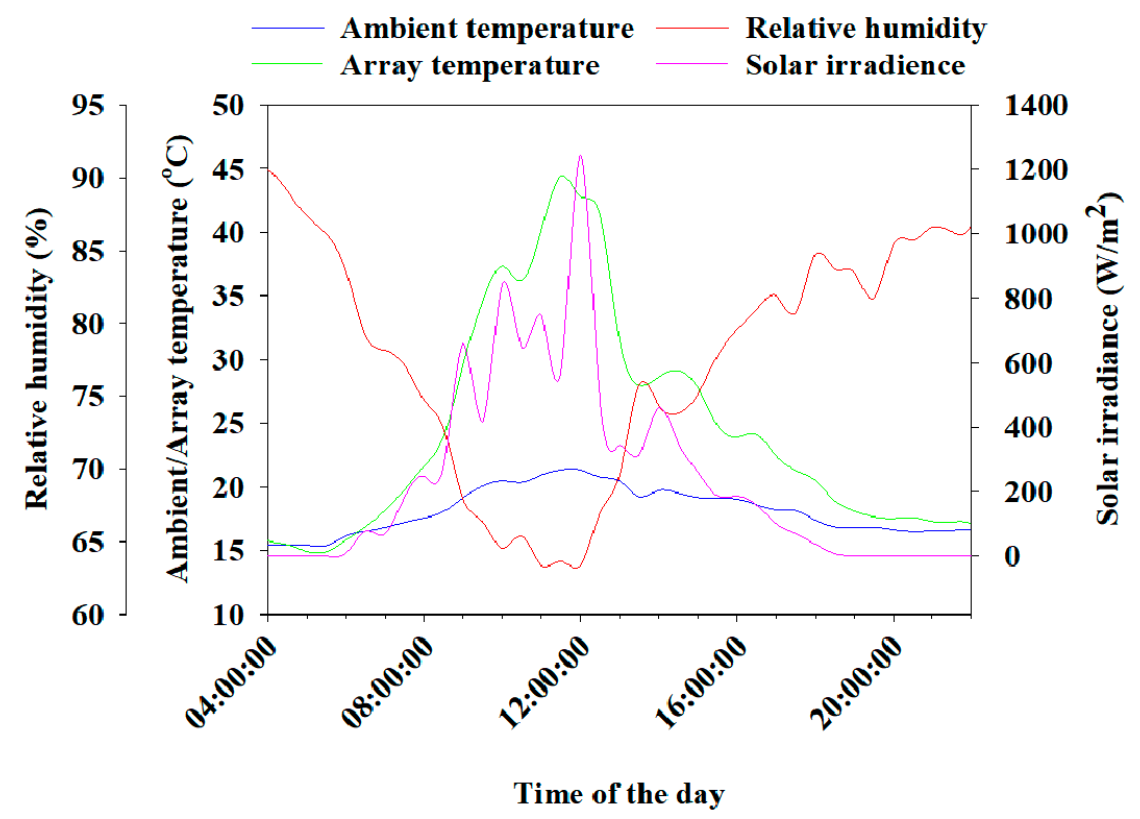

Figure 13. Measured data from CR1000 data logger during a rainy day in February 2018 at the University of Fort Hare, South Africa.

The curves depict that the array temperatures are nearly similar to the ambient temperature at a zero solar irradiance. But immediately the solar irradiance rises, the array temperature increases and becomes more than the ambient temperature.

\subsection{Electrical Performance of the PV Power Plant}

The solar radiation and module temperature are the main influencing factors affecting PV power production [33]. PV current curve does not always follow the irradiance curve directly throughout the day as expected since the photo-generated current is directly proportional to solar irradiance. However, the connected load also determines the amount of current released by the PV module. PV open circuit voltage tends to decrease with an increase in the module temperature [32]. The current and voltage distribution of the $\mathrm{PV}$, charge controller and battery over the reporting period are presented in Figure $14 a-c$.

In Figure 14, the negative battery current depicts charging whereas load supply (discharging) was represented with a positive current. Comparison of Figures 11 and 14 indicate that the PV voltage increases with the increase in solar irradiance in all systems. At midday which corresponds with peak module temperature, a slight dip of the systems' voltages was also observed. Furthermore, the PV current appeared to have increased with the solar radiation but dropped by approximately half around midday. Based on the typical operation of MPPT charge controllers, the systems' charge controllers continuously monitor the PV power level and batteries state of charge. A Boost charging mode was 
induced by the charge controller; having detected a low battery and available PV power at sunrise [32]. This created a dummy load for the PV and the resulting large amount of current flow.

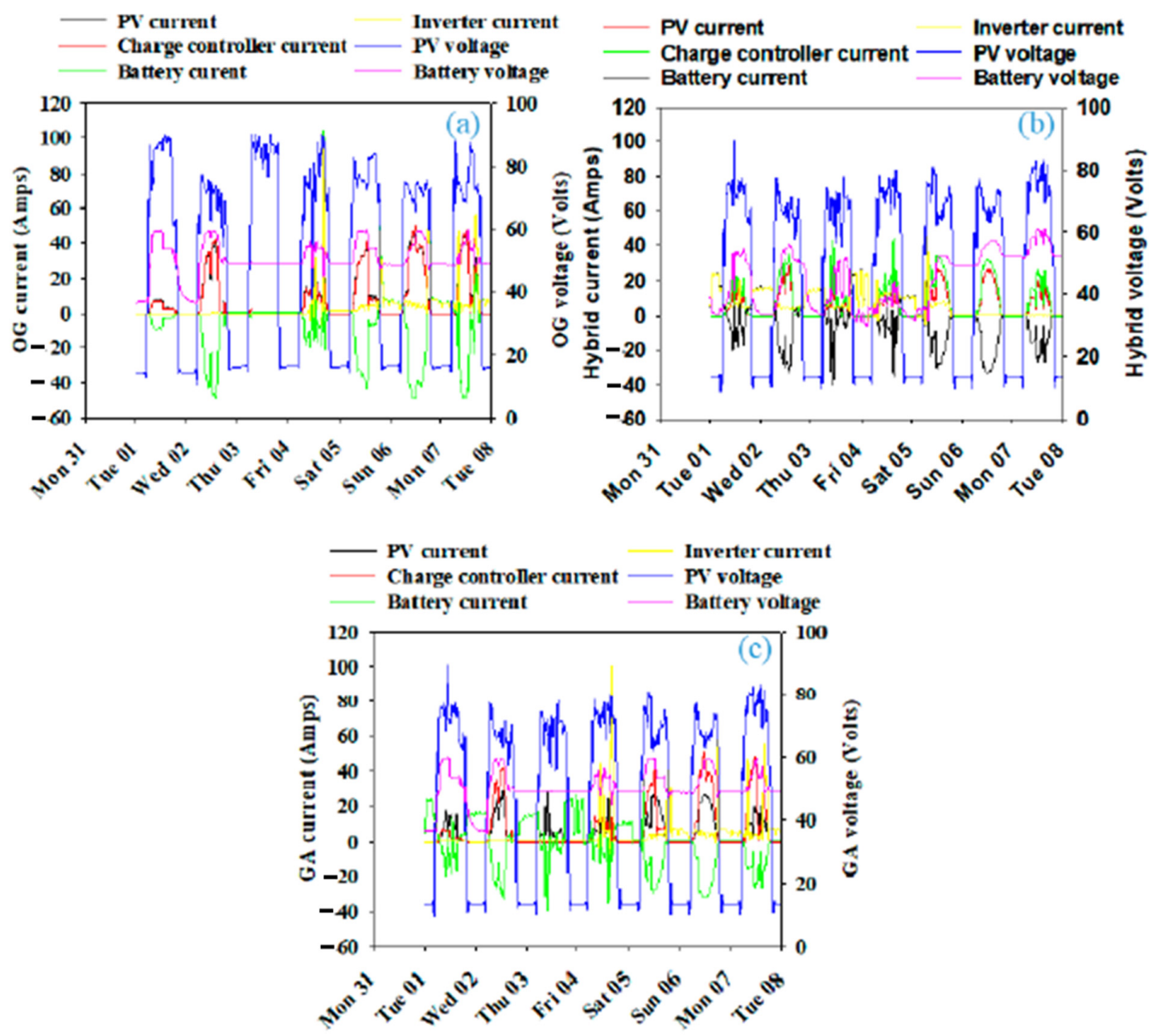

Figure 14. Voltage and current distributions of (a) off-grid system, (b) grid-assisted system and (c) hybrid system.

At midday, the charge controller sensed a fully charged battery and switches to Float or Sleep mode. At these modes, the charge controller prevents the PV with a smaller amount of load, thereby reducing the quantity of current flow. A similar phenomenon occurs in the three systems but varies according to the battery size (Ah), state of charge and connected load. The observed electrical performance of the PV systems is in line with the findings of [34]. In summary, during this one week, the designed DAS was noticed to be consistent and was able to observe all the meteorological and electrical sensors with high precision and can resist high temperatures and severe circumstances surrounding the environment like wind and heavy rain.

\section{Conclusions}

In this paper, a workable and reliable electrical and meteorological DAS of PV-based microgrid has been established and installed as a prototype for rural energy accessibility projects. The designed DAS monitors parameters simultaneously from three PV power plants, thereby helping in limiting resources and technical skills. Besides, the simple design and easy installation make it freely accessible without the knowledge of a unique programming language. We have equally succeeded in combining mechanical, electric and electronic parts into an enclosed DAS box in an easy assembly kit. Calibration of the voltage signal conditioner shows a maximum difference of $1.5 \%$ between the actual and DAS, 
thereby making the systems meet up with the key necessities in terms of accuracy and dependability. The findings indicate that the PV current in all three systems were found to increase with the increase in solar irradiance, whereas the subjected load influenced the PV currents. Both the off-grid and grid-connected (hybrid and grid-assisted) were monitored by various shunts to adjust the measured data to the required data logger specifications. The designed DAS can be reliably used for PV performance monitoring for all parameters with a high degree of precision and equally capable of resisting high temperatures of about $45^{\circ} \mathrm{C}$ and challenging climatic environments like heavy rain and dust. One important future direction is to design real-time remote monitoring of electrical and meteorological DAS of PV microgrid for rural electrification projects.

Author Contributions: All authors contributed significantly to this study. Conceptualization, E.L.M. and O.O.A.; setup of the electrical data acquisition system, E.L.M. and O.O.A.; setup of the meteorological data acquisition system, E.L.M. and O.K.O.; periodic data collection and management, O.O.A. and O.K.O.; data analysis and graphs production, E.L.M. and O.K.O.; compilation of manuscript, O.O.A. and O.K.O.; technical review and editing of the manuscript, E.L.M. and O.K.O. All authors have read and agreed to the published version of the manuscript.

Funding: This work was based on the research supported in part by the National Research Foundation of South Africa (Grant number 116763). We also acknowledge the Department of Science and Technology and Govan Mbeki Research and Development Centre for supporting this research.

Acknowledgments: Special thanks to the members of staff and the students of the Fort Hare Institute of technology for their technical support of this research.

Conflicts of Interest: The authors declare no conflict of interest.

\section{References}

1. Soumia, B.; Nallapaneni, M.K.; Ali, T. Data acquisition system: On the solar photovoltaic module and weather parameters monitoring. Proc. Comput. Sci. 2018, 132, 873-879. [CrossRef]

2. Fuentes, M.; Vivar, M.; Burgos, J.M.; Aguilera, J.; Vacas, J.A. Design of an accurate, low-cost autonomous data logger for PV system monitoring using ArduinoTM that complies with IEC standards. Sol. Energy Mater. Sol. Cells 2014, 130, 529-543. [CrossRef]

3. Sarma, P.; Singh, H.K.; Bezboruah, T. A Real-Time Data Acquisition System for Monitoring Sensor Data. Int. J. Comput. Sci. Eng. 2018, 6, 539-542. [CrossRef]

4. Blaesser, G. PV system measurements and monitoring the European experience. Sol. Energy Mater. Sol. Cells 1997, 47, 167-176. [CrossRef]

5. Kim, M.; Hwang, E. Monitoring the battery status for photovoltaic systems. J. Power Sources 1997, 64, $193-196$. [CrossRef]

6. Wilshaw, A.R.; Pearsall, N.M.; Hill, R. Installation and operation of the first city centre PV monitoring station in the United Kingdom. Sol. Energy 1997, 59, 19-26. [CrossRef]

7. Kumar, N.M. Simulation tools for technical sizing and analysis of solar PV systems. In Proceedings of the 6th World Conference on Applied Science, Engineering and Technology, UMPO, Ponorogo, Indonesia, 26-27 August 2017; pp. 218-222.

8. Manoj Kumar, N.; Sudhakar, K.; Samykano, M. Techno-economic analysis of 1 MWp grid connected solar PV plant in Malaysia. Int. J. Ambient. Energy 2019, 40, 434-443. [CrossRef]

9. Shariff, F.; Abd, N.; Wooi, H. Expert Systems with Applications Zigbee-based data acquisition system for online monitoring of grid-connected photovoltaic system. Expert Syst. Appl. 2015, 42, 1730-1742. [CrossRef]

10. Ahmed, C.B.; Kassas, M.; Ahmed, S.E. PV-standalone monitoring system performance using LabVIEW. Int. J. Smart Grid Clean Energy 2014, 3, 44-50. [CrossRef]

11. Van Dyk, E.E.; Gxasheka, A.R.; Meyer, E.L. Monitoring current-voltage characteristics and energy output of silicon photovoltaic modules. Renew. Energy 2005, 30, 399-411. [CrossRef]

12. Sumithra, G.R.; Poornima, S. Embedded Based Temperature Monitoring System. Int. J. Eng. Sci. Invent 2018, 7, 86-90.

13. Singh, H.K.; Gogoi, R.; Bezboruah, T. Design Approach for a Web-Based Distributed Data Acquisition and \& Control System. In Proceedings of the International Conference on Internet Computing, Las Vegas, NV, USA, 13-16 July 2009; pp. 16-19. 
14. Falk, A.; Durschner, C.; Remmers, K.H. Photovoltaics for Professionals: Solar Electric Systems Marketing, Design and Installation; Routledge: Abingdon, UK, 2013.

15. Casadei, D.; Grandi, G.; Rossi, C. Single-phase single-stage photovoltaic generation system based on a ripple correlation control maximum power point tracking. IEEE Trans. Energy Convers. 2006, 21, 562-568. [CrossRef]

16. Cabrera-Tobar, A.; Bullich-Massagué, E.; Aragüés-Peñalba, M.; Gomis-Bellmunt, O. Review of advanced grid requirements for the integration of large scale photovoltaic power plants in the transmission system. Renew. Sustain. Energy Rev. 2016, 62, 971-987. [CrossRef]

17. Mahela, O.P.; Shaik, A.G. Comprehensive overview of grid interfaced solar photovoltaic systems. Renew. Sustain. Energy Rev. 2017, 68, 316-332. [CrossRef]

18. SANS 204. Energy Efficiency in Buildings, 1st ed.; South African Bureau of Standards: Pretoria, South Africa, 2011; ISBN 978-0-626-26403-1.

19. SOLARGIS. Solar Resource Maps of South Africa: Photovoltaic Electricity Potential. Available online: https://solargis.com/maps-and-gis-data/download/south-africa (accessed on 4 March 2018).

20. Overen, O.K.; Meyer, E.L.; Makaka, G.; Ziuku, S.; Mamphweli, S. Zonal Air Exchange Rate of a Passive Solar House and Resultant Sensible Air Heat Transfer. Indoor Built Environ. 2018, 20, 1-13. [CrossRef]

21. Rus-Casas, C.; Jiménez-Castillo, G.; Aguilar-Peña, J.D.; Fernández-Carrasco, J.I.; Josémuñoz-Rodríguez, F. Development of a prototype for monitoring photovoltaic self-consumption systems. Electronics 2020, 9, 67. [CrossRef]

22. Tang, W.; Yang, K.; He, J.; Qin, J. Quality control and estimation of global solar radiation in China. Sol. Energy 2010, 84, 466-475. [CrossRef]

23. Kipp \& Zonen. Instruction Manual_Pyranometer and Albedometer; Delftechpark: Delft, The Netherlands, 2015.

24. Campbell Scientific INC. Solar Radiation Shields: For Temperature/Relative Humidity Sensors; Logan Publishing Company: Logan, UT, USA, 2015.

25. Moser, Y.; Gijs, M.A.M. Miniaturized flexible temperature sensor. J. Microelectromech. Syst. 2007, 16, 1349-1354. [CrossRef]

26. Yamazoe, N.; Shimizu, Y. Humidity Sensors: Principles and Applications. Sens. Actuators 1986, 10, 379-398. [CrossRef]

27. Buma, C.L. Performance Evaluation of an Off-grid Building Integrated Photovoltaic System. Master's Thesis, University of Fort Hare, Alice, South Africa, 2018.

28. Schnieders Electric. A9MEM3155 IEM3155 Energy Meter-63 A-Modbus—1 Digital; Schnieders Electric: Paris, France, 2019; pp. 1-3.

29. Schnieders Electric. A9MEM2150 Modular Single Phase Power Meter; Schnieders Electric: Paris, France, 2019; pp. 1-2.

30. Stoyanov, S. Software Tools for Mechanical Structures Resonant Frequencies Determination: Vibration Signal Processing for Modal Analysis. In Proceedings of the 19th International Conference on Computer Systems and Technologies, Ruse, Bulgaria, 13-14 September 2018; pp. 120-123.

31. Fang, L.; Clausen, G.; Fanger, P.O. Impact of Temperature and Humidity on the Perception of Indoor Air Quality. Indoor Air 1998, 8, 80-90. [CrossRef]

32. Fanourakis, S.; Wang, K.; McCarthy, P.; Jiao, L. Low-cost data acquisition systems for photovoltaic system monitoring and usage statistics. Conf. Ser. Earth Environ. Sci. 2017, 93, 1. [CrossRef]

33. Bevilacqua, P.; Morabito, A.; Bruno, R.; Ferraro, V.; Arcuri, N. Seasonal performances of photovoltaic cooling systems in different weather conditions. J. Clean. Prod. 2020, 272, 122459. [CrossRef]

34. Solanki, C.S.; Sangani, C.S.; Gunashekar, D.; Antony, G. Enhanced Heat Dissipation of V-Trough PV Modules for Better Performance. Sol. Energy Mater. Sol. Cells 2008, 92, 1634-1638. [CrossRef]

Publisher's Note: MDPI stays neutral with regard to jurisdictional claims in published maps and institutional affiliations. 